\section{Nine years of DentEd - a global perspective on dental education}

\author{
P. A. Reynolds, ${ }^{1}$ K. A. Eaton, ${ }^{2}$ C. Paganelli ${ }^{3}$ and D. Shanley ${ }^{4}$
}

VERIFIABLE CPD PAPER
IN BRIEF

- Describes a nine year long series of projects that have led to a new approach to dental education in Europe.

- Details how the further development and use of e-learning was seen as a key goal.

- Considers how the future dental curriculum should be based on competences to be achieved rather than the processes used to achieve them.

- Explains how the work of the projects will be continued in the future.

This paper describes the three successive and successful DentEd projects, funded by the European Union, that established a productive thematic network which identified common content within the dental curriculum. It then developed an agreed professional profile, with a defined set of competences and a modular curriculum for all new dental graduates based on the European Credit Transfer System and trends in learning and assessment. The three phases took nine years to complete. Phase one investigated all aspects of dental undergraduate education and included over 30 visits to different dental schools by teams of dental educators. Phase two built on this work and included further visits to dental schools. Phase three refined the competency framework that had been developed in phase two and culminated in a global dental conference which finalised position papers on all aspects of dental education. The work and recommendations of the ICT in dental education group are considered in detail in the paper. The projects provided the stimulus for a number of European and international collaborations, including the web-based International Federation of Dental Education and Associations (IFDEA) Knowledge Centre and the International Virtual Dental School (IVIDENT), both of which aim to make increasingly sophisticated ICT-based educational material available worldwide and to promote international understanding.

\section{E-LEARNING IN DENTISTRY}

Section A: Teaching and technology

1. A description of the new technologies used in transforming dental education

2. Seeing is believing: dental education benefits from developments in videoconferencing

3. Webcasting: casting the web more widely

4. Top of the pops - CD-ROM and DVDs in dental education

Section B: Informatics: better informed by systems and services

5. Better informed: an overview of health informatics

6. Better informed in clinical practice a brief overview of dental informatics

7. Digital clinical records and practice administration in primary dental care

Section C: Impact of e-learning in

dental education

8. Remember the days in the old school yard: from lectures to online learning

9. An intricate web - designing and authoring a web-based course

10. The many faces of interaction

11. Supporting the learner and teacher online

12. Making a mark - taking assessment to technology

13. Continuing professional development and ICT: target practice

14. Assuring quality

Section D: A connected future

15. Nine years of DentEd: a global perspective

16. A vision of dental education in the third millenium

\section{INTRODUCTION}

In September 2007, a global dental congress, held in Dublin, marked the completion of the DentEd project. There have been three DentEd projects, all of which were funded as part of a European Union (EU) programme, specifically the SOCRATES II initiative, that supports educational co-operation across Europe encompassing all levels from primary school through to higher education, and covering many issues from technologies to adult learners. ${ }^{1}$ The DentEd initiative emanated from a group of dental academics across Europe seeking collaboration on a web-based European approach to dental education.

Within the SOCRATES II initiative, the ERASMUS programme is concerned

\footnotetext{
${ }_{1 *}$ Professor of Dental Education, Centre for Flexible Learning in Dentistry, King's College London Dental Institute, Floor 3, Strand Bridge House, 138-142 The Strand, London WC2 $1 \mathrm{HH}$; ${ }^{2}$ Visiting Professor, UCL Eastman Dental Institute, 256 Gray's Inn Road, London, WC1X 8LD/Honorary Professor, University of Kent ${ }^{3}$ Professor of Orthodontics, Dental School, University of Brescia, Pza Spedali Civili 1, 25131 Brescia, Italy; ${ }^{4}$ Professor Emeritus, Dublin Dental School and Hospital, Trinity College Dublin, Lincoln Place, Dublin 2, Ireland ${ }^{*}$ Correspondence to: Professor P. A. Reynolds Email:P.A.Reynolds@kcl.ac.uk
}

\section{Refereed Paper}

DOI: 10.1038/sj.bdj.2008.698

${ }^{\circledR}$ British Dental Journal 2008; 205: 199-204 with two main objectives. ${ }^{1}$ These are:

1. To support European activities of higher education institutions

2. To promote the mobility and exchange of their teaching staff and students.

While the principle of mobility remains central to ERASMUS, its purpose is now to integrate this concept "into a wider framework of co-operation activities which aim at developing a "European dimension" within the entire range of a university's academic programmes.' The emphasis is, therefore, changing towards 'teaching staff exchanges, transnational curriculum development and pan-European thematic networks.'

All the current $27^{*}$ EU member states participate in ERASMUS along with Iceland, Lichtenstein, Norway and Turkey. Between 1987 and 2004, no less than one million university students spent an ERASMUS period abroad and by 2006, over 2,000 universities (or other higher education institutions) took part in the programme. ${ }^{1}$

*When the DentEd project commenced the EU consisted of 15 member states; for this reason the states that have joined the EU since 2004 were initially treated as Associate Members of the DentEd project 
European educational initiatives have been influenced by the Bologna Declaration, a joint declaration of the European ministers of education ${ }^{2}$ on higher education in Europe. The Declaration aims at 'increasing the international competitiveness of the European system of higher education' and stresses the need for the system to acquire 'a world-wide degree of attraction equal to our extraordinary cultural and scientific traditions. ${ }^{2}$

The Declaration has a target of achieving a number of objectives to "establish the European system of higher education worldwide' by 2010. ${ }^{2}$ Among these are:

- Adoption of a system of easily readable and comparable degrees

- Adoption of a system essentially based on two main cycles, undergraduate and graduate

- Establishment of a system of credits - such as in the European Credit Transfer System (ECTS) ** - as a proper means of promoting the most widespread student mobility

- Promotion of mobility by overcoming obstacles to the effective exercise of free movement

- Promotion of European co-operation in quality assurance

- Promotion of the necessary European dimensions in higher education, particularly with regards to curricular development, inter-institutional co-operation, mobility schemes and integrated programmes of study, training and research.

However, for dentistry, the Declaration $^{2}$ presents a conundrum with its recommendation for a bachelor degree after three years study as opposed to the requirement of the relevant European Commission (EC) training directive ${ }^{3}$ that the undergraduate course for dentistry should be a five year, full-time course. There are no simple solutions, but the DenEd projects offered a positive and successful thematic network that identified common content based on an agreed professional profile with a defined set

\footnotetext{
**ECTS, the European Credit Transfer and Accumulation System, is a student-centred system based on the student workload required to achieve the objectives of a programme, objectives preferably specified in terms of the learning outcomes and competences to be acquired.
}

of competences and modular dental curriculum based on the credit transfer system and the current education trends in learning and assessment. ${ }^{4}$ This paper will now describe the general principles of the DentEd project(s) and their contribution to the development of the use of ICT in dental education.

\section{DENTED 1}

DentEd took the precepts of the ERASMUS programme and applied them to dental education. Prior to the start of the DentEd project, the European Commission had been advised by the Advisory Committee on the Training of Dental Practitioners (ACTDP). Its membership was composed of three representatives from the profession, the competent authority and a university nominee from each member state. They identified a number of problems relating to the variability of undergraduate dental education in Europe and published a paper to highlight them. ${ }^{5}$ When funding for the ACTDP was suspended by the EC, a number of its members inaugurated the DentEd project under the leadership of Professor Diarmuid (Derry) Shanley. The primary aim of DentEd was 'to facilitate and assist dental schools to converge towards higher standards in undergraduate dental education, science and scholarship through the pooling of intellectual resources, sharing experiences and resources, exchanging and promoting better understanding of education and training in the context of their own regional priorities. ${ }^{6}$

Described as a 'thematic network on European dental education, ${ }^{6}$ the DentEd project has subsequently run in three three-year phases - DentEd; DentEdEvolves; and DentEd III. As mentioned previously, the final phase was completed in September 2007. Its work now continues in Europe under the auspices of the Association for Dental Education in Europe (ADEE, www.adee.org) and, in a global context, the International Federation of Dental Educators and Associations (www.ifdea.org).

The project was comprehensive and covered virtually every aspect of undergraduate dental education. In the original phase, simply called DentEd, peer review visits were made to over fifty European dental schools with a particular emphasis on the 'accession' countries who had applied for membership of the EU. The results were discussed, during a DentEd conference at the Nobel Institute in Stockholm in 2000, by 19 working groups who considered a wide range of topics relating to all aspects of undergraduate dental education (clinical, research, administrative, etc) (Fig. 1). A series of recommendations was made, goals were set and the conference concluded by looking forward to a second phase of DentEd (DentEdEvolves). They also sought to involve the American Dental Education Association (ADEA) and the South East Asian Association for Dental Education (SEAADE).

\section{DentEd 1 - vive la difference?}

The conference held at the end of phase one, based on the results of school visits, concluded that there were enormous differences in the organisational structure of dental schools within the European Union, the European continent, and sometimes within a single country. ${ }^{8}$ The only common features were that they were usually part of a university (except for some central and eastern European countries) and that the state "usually determines the basic curricular requirements and supervises the framework of the curriculum, or at least the requirements for the final qualifying examination before registration.' ${ }^{8}$

The working group on organisational structures identified three innovations. ${ }^{8}$ These were:

1. A process whereby junior staff and students contribute to the development of ideas and innovations in dental teaching

2. A defined system of internal, formal quality assurance for all aspects of teaching and education

3. Integration of teaching for all dental healthcare professionals (ie dental undergraduates with hygienists or other dental auxiliaries - dental inter-professional education).

In its recommendations this working group noted the need to identify developments and innovations in progressive dental education with the ability to flexibly integrate them into the curriculum. 
They specifically mentioned 'virtual' training systems in biology, anatomy, basic sciences and clinical techniques, computer-assisted learning, web-based training, CD-ROM and the use of other media. ${ }^{8}$ Thus the project foresaw the importance of e-learning in the undergraduate dental curriculum.

It also proposed 'proper clinical facilities supporting dental education of healthcare professionals, ${ }^{, 8}$ while 'organisational structures of the dental school should support the internationalisation and European (and global) convergence in standards of dental education by lively exchange programmes for faculty and students, acceptance of appropriate credit transfer systems (eg ECTS) and, finally, by bilingual teaching and learning.' ${ }^{\circ}$

\section{DentEd 1 - variety}

The working group on educational methods opened their report with the words: 'The way in which dental education is delivered would appear to be as varied as the number of dental schools in Europe.'

In one area there appeared to be little variation and that was in the teaching methods employed - a combination of lectures, group sessions and clinical sessions. As a result, among the best practices stressed by the working group were:

- Self-directed learning programmes for students

- Small group teaching/learning

- Personal freedom for teaching and learning with 24-hour access to all facilities.

The future value of problem-based teaching/learning (PBL) was emphasised together with the incorporation of evidence-based learning/treatment in the curriculum, both designed to ensure "the active role of the student in the learning process. ${ }^{9}$ However, as they point out, "this implies that all staff members and students should have basic knowledge of information and communication technologies (ICT) and the ability to search for current information through the Internet and Intranet. ${ }^{9}$ They further claimed that "the introduction of PBL into the curriculum can usefully be supported by

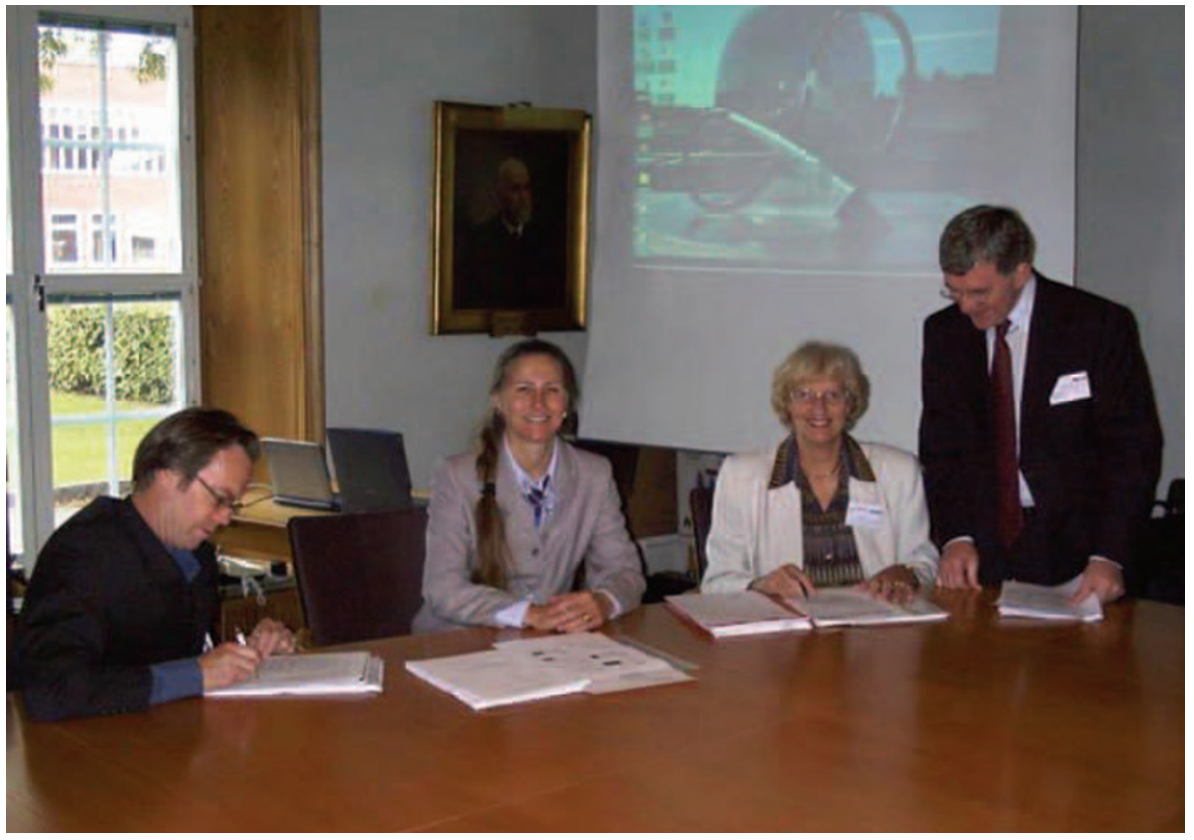

Fig. 1 Working group 19 on 'other influences and student affairs' in Stockhom 2000 was chaired by Dame Margaret Seward (second from right), with Dr Pat Reynolds (UK, second from left) as Rapporteur and member Dr Henk Kersten (left) from the Netherlands. The group was visited by Derry Shanley (right)

special CD-ROM programmes, the use of computer-assisted teaching, instructive computer programmes for practical procedures and learning programmes with self-control functions. This also facilitates self-directed learning.' 9

Thus it can be seen that by 2000, those involved in the DentEd project had a clear understanding of the importance of ICT in dental education.

\section{DENTEDEVOLVES - A VISION OF THE USE OF ICT IN THE UNDER- GRADUATE DENTAL CURRICULUM}

In the next phase - DentEdEvolves - more attention was paid to the key aspects of ICT and its role in assessment and quality improvement. As part of this phase of the project, an analysis of the current situation was made during a global congress held in Prague in 2001. Representatives from 160 dental schools or stomatological institutes took part (Fig. 2) and considered five themes. One of the themes was 'the virtual potential'. Within this theme, four specific aspects, all related to ICT, were discussed by working groups. They were:

1. Web-based interactive learning programmes

2. Clinical records and global diagnostic codes

3. Towards a global superstore of quality - assured modularised learning programmes

4. Electronic management systems.

In their report, the working group, charged with considering web-based interactive learning programmes, stressed the points that 'ICT offers added value that cannot be obtained by any other means' and that potentially there was 'virtually unlimited use of image and video installations of clinical procedures and biological phenomena, more or less independent of time or place. ${ }^{10}$

However, there are always the dangers that ICT can become the master rather than the servant, that it can encourage a 'cutand-paste' approach to compiling teaching material and that, despite its undoubted potential, investment in it can be wasted. The working group attempted ${ }^{10}$ to avoid these pitfalls by posing and answering a number of questions relating to:

- Tools for learning and communications

- Important content characteristics

- Development and implementation of networked learning

- Evaluation of the electronically provided material and learning.

They concluded that ICT must enhance and enrich learning, not diminish it. ${ }^{10}$ 


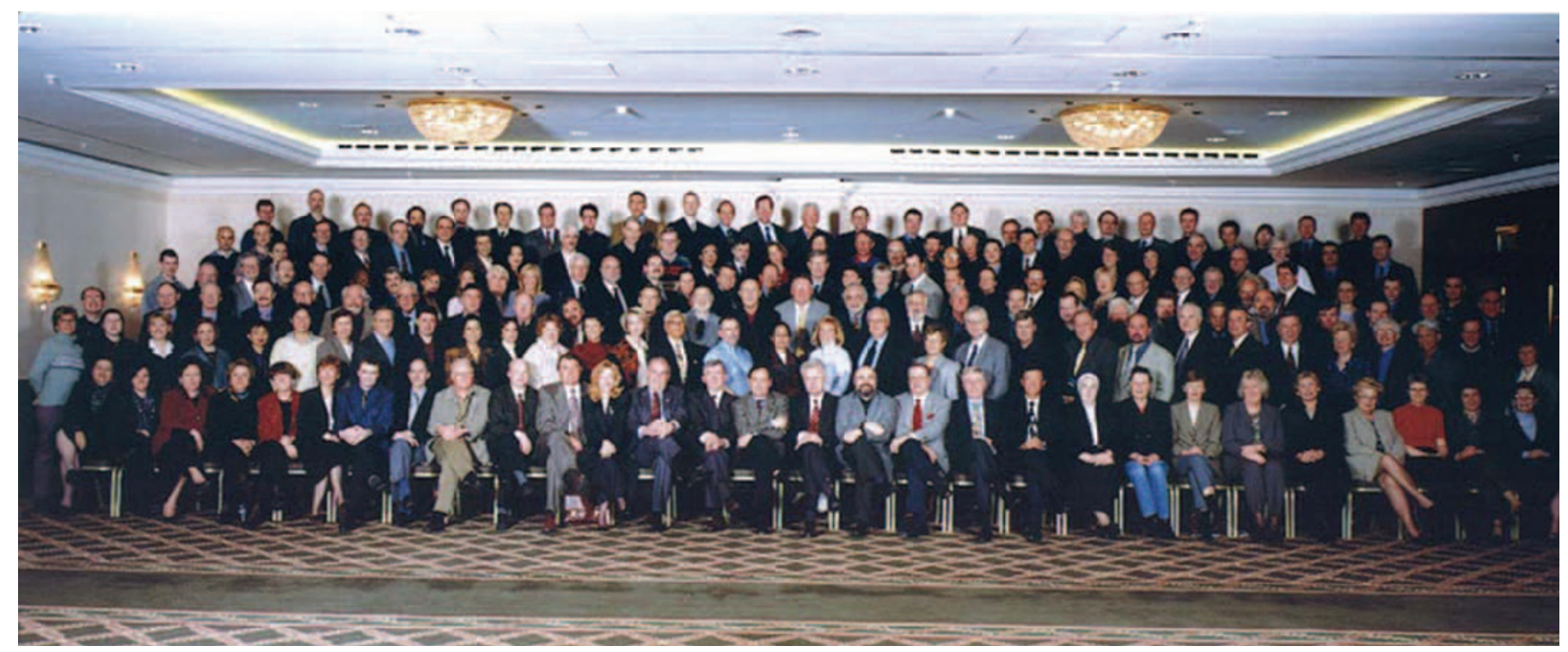

Fig. 2 Delegates at the Global Congress in Prague in 2001

They also agreed that ICT should be 'employed appropriately to meet learning objectives' and, finally, that 'it should be made available to all faculty teachers and students along with appropriate instruction in their use. ${ }^{10}$

To avoid 'cut-and-paste' courses they recommend 'Database packages of images and texts must be linked to the evidencebased literature and to other similar databases of the same content. This principle will allow students to compare information provided from several sources. ${ }^{10}$ In addition, they suggested that 'Each image in any database must meet certain standards, ie quality or image resolution. All images must describe defined conditions and include interactive options to guide and assist the learning process. A consistent layout of the descriptive text and the evidence base must be linked to the images. The level of interactivity between text and image should be relative to the skill level of the learner. ${ }^{10}$

The working group on electronic management systems saw a major impact of ICT in facilitating learning and the management of resources involved in the learning process. ${ }^{11}$ They stressed the linkage between clinical practice undertaken by students and the provision of information on students' progress, arguing that 'a totally computerised clinical operation will improve student evaluation, patient recall and efficiency of treatment. Early exposure of students to electronic information resources should help to produce practitioners with a different orientation towards knowledge and learning. ${ }^{11}$

The working group that discussed the concept of a global superstore of quality-assured modularised learning programmes suggested that 'a global movement towards higher standards in dental education through pooling of intellectual resources, exchanging perceptions of best practices and sharing experiences in education, training, assessment methods and outcome analysis' would promote convergence of educational standards. ${ }^{12}$ ICT's role would be primarily through a recommended website that would make relevant information available universally, provide a database on best practices in dental education and make the methods for establishing standards generally available. They asserted that this web-based resource would allow 'schools, nations, and regions [to] have the opportunity to implement, as they so choose, standards which might realistically challenge them to converge towards the higher standards. ${ }^{12}$ To make this approach truly comprehensive, it was suggested that links could be established with curriculum content, competences and electronic record databases. ${ }^{12}$

There was significant interest from, and collaboration with, IFDEA during the DentEdEvolves phase. The global congress in Prague in $2001^{13}$ was followed by a second Global Congress on Dental Education in Singapore in 2002 facilitated jointly by IFDEA and DentEdEvolves.

\section{THE THIRD PHASE OF DENTED}

The potential of information technology in dental education was the topic for one working group during the 2007 Global Congress held in Dublin to mark the completion of the third and final phase of DentEd.

The discussions of the group included the instructional applications of IT in undergraduate and postgraduate dental education and all possible ways in which IT can assist in the education and competence development of dental students and dentists (eg e-learning, distance learning, simulations, computer-based assessments). ${ }^{14}$ A number of educational application-types were identified and are shown in the Table 1 together with the ICT tools they employ. ${ }^{14}$

In the position paper from the working group, the value of IT-based education was summarised under a number of headings - access issues, studentcentred, decision support. The consensus from these was that IT expands the accessibility of educational material and courses for both students and institutions, and that the curriculum and assessment can be individualised for students who can enjoy more information made available chairside. ${ }^{14}$

Despite these assertions, the question has to be asked: does ICT add value to the quality of education? Peer review can be used as a method of ensuring 'content validity, currency, the use of evidence-based data, and the use of best practices. ${ }^{14}$ 
Another answer to the problem lies with students, for as suggested by another working group at the Dublin congress, ICT offers them 'greater information retrieval and interaction with peers, colleagues or faculty. It is more appealing due to graphic interfaces, multimedia content and continuing software upgrades. ${ }^{15}$ However, it should not be seen as a "passive repository of infrequently updated PowerPoint presentations, ${ }^{15}$ but expanded to include: ${ }^{15}$

- Full and free access to electronic journals

- Access to computer facilities outside 'working hours'

- On-demand self-assessment modules or review courses via the Internet

- Implementation of electronic patient records and 'paperless clinics'

- Greater investment in infrastructure and staff and student ICT literacy.

\section{GOING GLOBAL}

As can be seen from the foregoing description, although DentEd began as a purely European initiative, it soon developed a global perspective and both phases two and three incorporated global congresses. Whilst it is likely that there will always be regional differences, at all these global congresses there was agreement of the need for convergence in dental education towards higher global standards. One recommendation from the Prague 2001 congress was to "provide interested parties with a resource containing sets of standards used by different regions, countries, and/or schools against which to assess their own standards. ${ }^{12}$ It was also suggested that a similar approach should be possible with 'databases detailing best practices. ${ }^{12}$

One of the obstacles to overcome at all levels, national, continental and global, is the 'not-invented-here' syndrome, ${ }^{10}$ ie the reluctance by some dental schools to accept teaching material from external sources. As far as ICT is concerned, it was suggested that there might be a number of ways of overcoming the problem, including: ${ }^{10}$

- Realistic global standards for the use of ICT in dental education

- Quality assured content standards for animations, design, technique, content, pedagogy, special software

Table 1 Educational application types identified at the 2007 Global Congress in Dublin and the ICT tools they employ

\begin{tabular}{|c|c|}
\hline Application & Tools \\
\hline Foundational knowledge acquisition (theoretical) & $\begin{array}{l}\text { Information retrieval and management } \\
\text { Stand-alone CAL systems, eg CD-ROMs } \\
\text { e-Learning platforms } \\
\text { Consumer electronics, eg iPods }\end{array}$ \\
\hline Acquisition of skills (pre-clinical and clinical) & Two- or three-dimensional simulations \\
\hline Patient care and decision-making & $\begin{array}{l}\text { Information retrieval and management } \\
\text { Teleconferencing }\end{array}$ \\
\hline Formative and summative assessment & $\begin{array}{l}\text { Administration and learning management systems } \\
\text { Computer-based assessment } \\
\text { Computer-based reflective logs, diaries, portfolios etc }\end{array}$ \\
\hline Information sharing & $\begin{array}{l}\text { Teleconferencing for collaborative working environments } \\
\text { File share applications }\end{array}$ \\
\hline
\end{tabular}

- Development and implementation of networked learning using physical resources (eg IT hardware and videoconferencing) and human resources (eg groups for hardware maintenance, multimedia instructional design and database management). ${ }^{8}$

To be truly global, such standards would have to be applicable in emerging countries as well as the developed world. ${ }^{10,12,16}$ The key consideration was seen as the ability to access world-class expert knowledge, provided a suitable ICT infrastructure was in place. The outcome should be 'an organic or growing electronic database containing worldwide information relating to standards in dental education. ${ }^{12}$ Full globalisation of dental education standards would entail commensurate levels of ICT skills, systems and services in the developing world. To achieve this it was suggested that 'International collaborative efforts should focus on the support and transfer of ICT infrastructure and know-how for application in low income regions. ${ }^{15}$

The work of the global congresses will continue through the website of the International Federation of Dental Educators and Associations (IFDEA) and through its global knowledge centre ${ }^{17}$ (www.ifdea.org).

\section{COLLABORATION}

One of the major benefits of DentEd has been the networking opportunities for dental academics and professionals.
Through this they have come to understand the differences and similarities between dental education across Europe and globally. This has encouraged a number of collaborative initiatives, including one between the dental schools of King's College London and the Universita' degli Studi di Brescia. Its aim is 'to develop codes of enterprise in clinical practice, teaching and research that reflect the principles of the Bologna Declaration. ${ }^{18}$

At an initial focus meeting for this collaboration held in 2003, two topics were addressed. They were:

1. Undergraduate and postgraduate study

2. Dental care professionals (DCPs) and teamcare.

During discussions it became clear that existing course modules with translation and undertaking student and professional exchanges would enhance the understandings between schools. ${ }^{, 18}$

In addition, a number of subjects were delineated that pointed to future collaborative developments. These were: ${ }^{18}$

- Prospective collaboration and exchanges between Italian and English dental hygiene courses

- Pilot dental nurse training courses

- Masters courses in dental technology

- Combining language studies with clinical work for undergraduates

- Translation of existing English postgraduate learning courses modules into Italian 


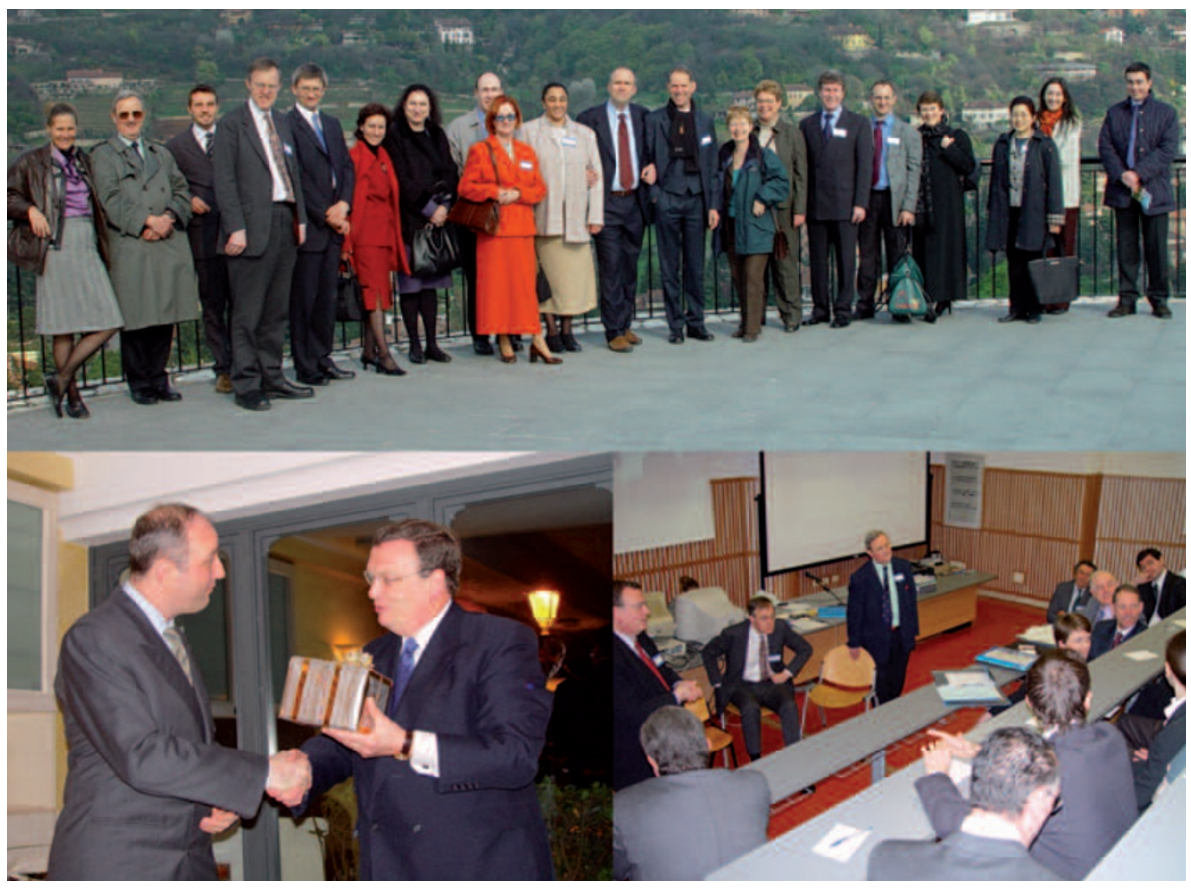

Fig. 3 Anglo Italian Colloquium 2003. From Top clockwise: A group of delegates; Workgroup on Policy; Deans Corrado Paganelli and Nairn Wilson exchanging tokens of appreciation

- Short courses and continuing professional development (CPD) training

- Indentifying possible researchfunding streams.

These focus meetings have subsequently become annual events with considerable progress being made in achieving the initial aim. Among the achievements has been the development of an online ethics course ${ }^{19}$ with research contributions into its effectiveness from not just King's College and Brescia, but also from the Open University and Australia's Curtin University of Technology in Perth. In addition, one of King's College London's online Masters courses - MClinDent (Fixed and Removable Prosthodontics) ${ }^{20}$ - has been translated into Italian.

Another key initiative has been the reconstitution of the IFDEA at the Global Conference in Dublin in 2007; for details visit www.ifdea.org. IFDEA seeks to improve global health by improving oral health, by sharing knowledge within the global dental education community. One of its initiatives is to set up a knowledge centre - a web-based resource designed to share knowledge and facilitate a better understanding of issues of diversity and inequality in oral healthcare and education. In collaboration with IVIDENT (the International Virtual Dental School), a non-profit making innovative global solution funded by the Higher Education Funding Council of England (HEFCE) and the Department of Health, significant opportunities to achieve shared aims are now possible.

Apart from such networking and collaboration, DentEd has provided many opportunities for participants to focus on the many issues affecting dental education, not least ICT and e-learning, and, through access to the vast corpus of differing knowledge and experience inherent within the project, commence and advance the process of providing solutions to them. IVIDENT now has the potential, with current levels of technological sophistication and international understanding, to achieve far more than the aspirations which led to the original DentEd submission.

1. The European Commission. 'What is Socrates/ Erasmus?' webpage. http://ec.europa.eu/ education/programmes/socrates/erasmus/what_ en.html (accessed 4 July 2008).
2. Confederation of EU Rectors' Conferences/Association of European Universities. The Bologna Declaration on the European space for higher education: an explanation. http://ec.europa. eu/education/policies/educ/bologna/bologna.pdf (accessed 17 March 2007).

3. European Council. European Council Directive number 78/686/EEC. Official Journal of the European Communities 1978; 21: L233. ISSN 0378-6978.

4. Ferrillo $\mathrm{P}$, Jones $\mathrm{M}$, McLoughlin J et al. Global congress on dental education and launch of a global network. Eur J Dent Educ 2008; 12(Suppl 1): 3-4.

5. Shanley D B, Barna S, Gannon P et al. Undergraduate training in the European Union - convergence or divergence? Eur J Dent Educ 1997; 1: 35-43.

6. Shanley D B. The DentEd thematic network project. In Shanley D B (ed) Dental education in Europe: towards convergence. pp 9-15. Budapest: Dental Press kft, 2001. ISBN 963-00-5305-5.

7. Shanley D B. The DentEd thematic network project. Epilogue: the next phase - towards globalisation. In Shanley D B (ed) Dental education in Europe: towards convergence. pp 164. Budapest: Dental Press kft, 2001. ISBN 963-00-5305-5.

8. Shanley D B. The DentEd thematic network project, chapter 3: organisational structures. In Shanley D $\mathrm{B}$ (ed) Dental education in Europe: towards convergence. Budapest: Dental Press kft, 2001. ISBN 963-00-5305-5.

9. Shanley D B. The DentEd thematic network project, chapter 5: educational methods. In Shanley D B (ed) Dental education in Europe: towards convergence. Budapest: Dental Press kft, 2001. ISBN 963-00-5305-5.

10. Nattlestad A, Attstrom R, Mattheos N et al. Webbased interactive learning programmes. Eur J Dent Educ 2002; 6(Suppl 3): 127-137.

11. Eplee H, Murray B, Revere J H et al. Electronic management systems. Eur J Dent Educ 2002; 6(Suppl 3): 152-160.

12. Oliver R, Paganelli C, Cerny D et al. Towards a global superstore of quality-assured modularized learning programmes. Eur J Dent Educ 2002; 6(Suppl 3): 147-151.

13. Shanley D, Nattestad A. DentEdEvolves global congress in dental education. Eur J Dent Educ 2002; 6(Suppl3): 5-6.

14. Mattheos N, Stefanovic N, Apse P et al. Potential of information technology in dental education. Eur J Dent Educ 2008; 12(Suppl 1): 85-92.

15. Ivaris K, Barlow P J, Chendea S A et al. The academic environment: the students' perspective. Eur J Dent Educ 2008; 12(Suppl 1): 120-130.

16. Reed M, Claffey N, Allen B et al. Towards global convergence of education, training, quality, outcome and assessment. Eur J Dent Educ 2002; 6(Suppl 3): 78-83.

17. International Federation for Dental Educators and Associations. Global Knowledge Centre website. http://www.ifdea.org/gkc/Pages/default.aspx (accessed 4 July 2008).

18. Reynolds P A, Paganelli C, Dunne S, Wilson N. The Anglo-Italian collaboration: a report of the first steps in implementing the Bologna Declaration. Eur J Dent Educ 2005: 9: 137-140.

19. Louca C, Reynolds P A, Coates R, Paganelli C, Cox $\mathrm{M} J$. Comparison of online activities between four different cohorts of dental students undertaking an international introductory ethics and professionalism course. (Poster 7). Proceedings of the Association of Dental Educators of Europe (ADEE) 32nd Annual Meeting, 30 Aug-2 September 2006, Krakow, Poland. Abstract p29.

20. King's College London. Fixed \&t Removable Prosthodontics MClinDent webpage. http://www. kcl.ac.uk/schools/dentistry/pg/distance/pros/ (accessed 10 April 2008). 